\title{
TOXOR: Design and Application of an Electrochemical Toxicity Biosensor for Environmental Monitoring
}

\author{
Tony O'Hara, ${ }^{[\mathrm{a}]}$ Brian Seddon, ${ }^{[\mathrm{c}]}$ Siobhán McClean, ${ }^{[\mathrm{b}]}$ and Eithne Dempsey*[a, c]
}

\begin{abstract}
Here we present design and assay methodology of a novel electrochemical biosensor with the view to assess cytotoxic effects of key chemicals. The concept is based on mammalian cells as the biological recognition agent (A549 human lung epithelial cells) and measures changes in cellular enzyme activity (acid phosphatase AP) following 24 hours exposure. AP catalyses the dephosphorylation of 2-naphthyl phosphate to 2-naphthol (determined using chronocoulometry) and is indicative of metabolically active cells. Immobilised living cells exposed to pentachlorophenol, cadmium chloride and nickel chloride exhibited a decrease in AP activity which
\end{abstract}

enabled $I C_{50}(50 \%$ reduction in enzyme activity) values of toxic chemicals to be reliably and conveniently determined using electronic detection. The $I C_{50}$ values obtained for $\mathrm{CdCl}_{2}$ and $\mathrm{NiCl}_{2}(65$ and $330 \mu \mathrm{M})$ were in agreement with those found using the standard MTT cytotoxicity assay $(100$ and $350 \mu \mathrm{M})$. In the case of pentachlorophenol, the value obtained $(60 \mu \mathrm{M})$ was lower (MTT assay $I C_{50}$ value $>160 \mu \mathrm{M}$ ) suggesting enhanced sensitivity of the electrochemical assay towards pentachlorophenol. It is envisaged that this device could be exploited in the screening of industrial and environmental toxins and has potential in drug testing applications.

Keywords: Cytotoxicity $\cdot$ Environmental toxin $\cdot$ Mammalian cell biosensor $\cdot$ Enzyme assay

\section{Introduction}

Monitoring of chemicals released into air, water and soil is a crucial element in understanding the effects that potential toxins have on human health and the environment [1]. In 2007, the European Union introduced the REACH directive EC (1907/2006) which aims to protect human health and the environment from potential risks posed by new and exisiting chemicals that are being manufactured and distributed in the EU, including nanomaterials. This directive puts the responsibilty on industry to manage any potential risks posed by such chemicals with provision of safety information. The directive also promotes the use of alternatives to animal testing during hazard assessment [2]. Chemical toxicity is normally assessed using animal models such as mice, fish or water fleas [3] or using in vitro cell cultures [4], with the latter being the preferred method for ethical and economic reasons [5].

A number of cell based cytotoxicity assays are currently in use - the most commonly used being the 3-(4,5-dimethyl-thiazol-2yl)-2,5-diphenyl-tetrazolium bromide (MTT) assay which measures the metabolic activity of cells following toxin exposure and is based on the reduction of tetrazolium, a yellow water soluble dye by the mitochondria of living cells to blue/purple coloured insoluble formazan crystals [6]. This reaction does not occur in metabolically inactive or dead cells. The amount of formazan generated by cells following toxin exposure is measured spectrophotometrically allowing the concentration of toxin that causes $50 \%$ reduction in cell viability $\left(I C_{50}\right.$ value) to be determined. Other commonly used cytotoxicity assays include lactate dehydrogenase (LDH), which measures release of cytoplasmic LDH from cells due to damage to the cell membrane upon toxin exposure [7] and the neutral red uptake assay measures a reduction in the amount of neutral red dye taken up by lysosomes following a cytotoxic insult $[8,9]$.

Electrochemical biosensors have the potential to provide toxicity information for key pollutants with applications in environmental monitoring [10]. Such analytical devices complement standard methods and offer advantages such as rapid response, specificity, ease of mass production, low cost and the ability to be employed on site $[11,12]$. A number of different biological recognition elements have been employed including enzymes, antibodies, bacterial and mammalian cells. A major advantage of using whole cells, in particular mammalian cells as biological recogntion elements is the relevance of these cells to human physiology and their ability to measure toxic effects from a wide range of chemicals [13-15].

[a] T. O'Hara, E. Dempsey

Centre for Research in Electroanalytical Technology (CREATE), Department of Science, Institute of Technology Tallaght

Dublin 24, Ireland

*e-mail: Eithne.dempsey@ittdublin.ie

[b] S. McClean

Centre for Microbial Host Interactions (CMHI), Department of Science, Institute of Technology Tallaght

Dublin 24, Ireland

[c] B. Seddon, E. Dempsey MiCRA-Biodiagnostics Technology Gateway Research Centre, CASH-Synergy Centre, Institute of Technology Tallaght (ITT Dublin)

Dublin 24, Ireland. 
A number of electrochemical techniques have been reported with the view to assess cell viability following exposure to cytotoxic agents. The use of electric cell substrate impedance sensing (ECIS) to monitor mammalian fibroblasts cells was first reported by Giaever and Keese [16]. ECIS sensing has been used by a number of researchers to monitor changes in cell viability upon exposure to cytotoxic drugs, nanomaterials and environmental toxins $[17,18,19]$.

Potentiometric biosensors have also been developed for cytotoxicity applications. Adlam et al. reported monitoring the effects of cycloheximide and campothecin on rheumatoid synovial fibroblasts (RSF) and HepG2 hepatocarcinoma cells by monitoring changes in the electrochemical open circuit potential at the microenvironment of the cell:sensor interface over 24 hours [20]. Wang et al. investigated the cytotoxic effects of hydroquinone towards chinese hamster lung fibroblast (V79) cells using a potentiometric sensor array [21]. A number of researchers have also reported measuring changes in electroactive species generation by cells upon exposure to toxins. A graphene/Nafion composite indium tin oxide modified electrode was developed by Yoon et al. and used to assess the cytotoxic effects of graphene nanoflakes by measuring changes in $\mathrm{H}_{2} \mathrm{O}_{2}$ generation by Hela cells [22]. Zhu et al. have developed a graphene modified glassy carbon electrode and used it to monitor xanthine and guanine leakage from Hela cells exposed to $\mathrm{Cr}, \mathrm{Cd}, \mathrm{Cu}, \mathrm{Pb}$ and $\mathrm{Zn}$ [23]. Yu et al. have also reported electrochemical detection of guanine in cells as a means to measure cytotoxicity of cyclophosphamide and arsenic trioxide [24].

Here we present a living cell electrochemical biosensor that has the ability to measure cellular enzyme acid phosphatase (AP) in A549 human lung epithelial cells as an indicator of viability. AP catalyses the conversion of the organic phosphate molecule 2-naphthyl phosphate (2-NP) to 2-naphthol and the redox active enzymatic product thus released is oxidised at a screen printed electrode sur- face and measured using cyclic voltammetry and chronocoloumetry (Scheme 1).

To the best of our knowledge there are no reports of a mammalian cell based biochip which exploits AP electrochemical detection to assess the cytotoxic effects of chemicals in living cells. Design and in-house fabrication (combined screen print/layer by layer lamination approach) of an integrated fluidic/detection system customised for the AP mammalian cell based assay leverages optimal electronic assay methodology. The prototype (TOXOR) presented requires integration and testing of both fluidic and detection elements culminating in five lab on a chip components (Scheme 2). The device takes advantage of low cost fabrication methods with the view to single use point-of-testing environmental toxicity monitoring.

\section{Experimental}

\subsection{Apparatus}

All electrochemical measurements employed a $\mathrm{CH}$ Instruments Inc $\mathrm{CH} 1630 \mathrm{C}$ potentiostat with single use carbon- $\mathrm{Ag} / \mathrm{AgCl}$ screen printed electrodes $\left(4 \mathrm{~mm}^{2}\right)$ or prototype TOXOR electronic sensing devices $\left(3.8 \mathrm{~mm}^{2}\right)$. Spectroscopic assays were made on transparent flat bottom 96 well plates (FL medical) using a Biotek synergy H1 Hybrid Reader.

\subsection{Reagents and Materials}

Sodium acetate $(\geq 99 \%)$, magnesium chloride hexahydrate $(\geq 98 \%)$, 2-naphthol $(\geq 99 \%)$, 2-naphthyl phosphate $(\geq 98 \%)$, pentachlorophenol (98\%), dimethyl sulfoxide $(\geq 99.6 \%)$, cadmium chloride (99.99\%), nickel chloride hexahydrate $(\geq 98 \%)$, phosphate buffered saline tablets, RPMI media containing $25 \mathrm{mM}$ HEPES, trypsin $0.5 \%$-EDTA $0.2 \%$, fetal bovine serum, penicillin 10000
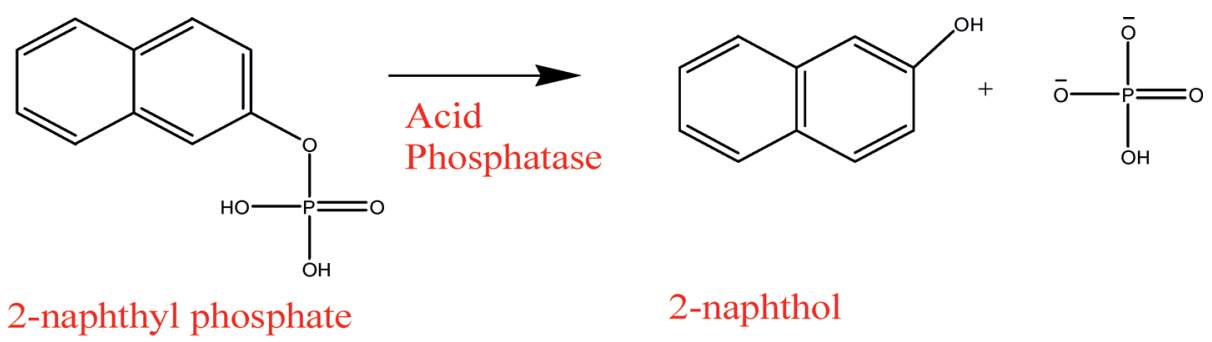

2-naphthol<smiles>Oc1ccc2ccccc2c1</smiles>

\section{2- naphthol oxidation at electrode surface}

Scheme 1. TOXOR enzyme detection sequence involving the enzymatic dephosphorylation reaction of 2-naphthyl phosphate substrate to 2-naphthol product by intracellular acid phosphatase followed by electrochemical oxidation. 


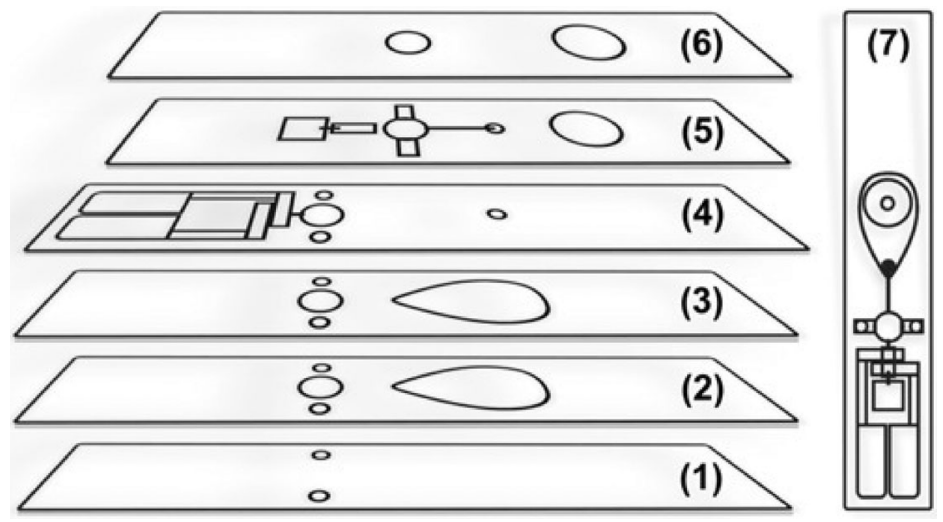

Scheme 2. Illustration of TOXOR device showing laminate construct method: (1) base layer, (2) and (3) reagent cavity layers, (4) electrode layer, (5) fluidic channel, (6) cover layer and (7) fully assembled TOXOR device (size $15 \mathrm{~mm} \times 81 \mathrm{~mm}$ ).

units per $\mathrm{ml} / \mathrm{streptomycin} 10 \mathrm{mg}$ per $\mathrm{ml}$, L-glutamine $200 \mathrm{mM}$, polystyrene (35000 Daltons) were all obtained from Sigma Aldrich. Silver/Silver chloride and carbon ink were supplied by Gwent, polyester 339 white $250 \mu \mathrm{m}$ and polyester O $100 \mu \mathrm{m}$ were Melinex brand. Polyester A grade $500 \mu \mathrm{m}$ was Mylar brand. Other chemicals and suppliers used included acetic acid (99\% Riedel de Haen), tetrahydrofuran (99.9\% Lab scan analytical sciences), Scotch Crystal $19 \times 66 \mathrm{~mm}$ tape, $0.22 \mu \mathrm{m}$ hydrophilic filters (Whatman) and $3 \mathrm{M}$ adhesive A4 sheets.

\subsection{Cytotoxicity Assay Development}

\subsubsection{Electrochemical Characterisation of 2-Naphthol}

A series of 2-naphthol standards $(0-500 \mu \mathrm{M})$ were prepared in $\mathrm{pH} 4.5$ acetate buffer $(0.1 \mathrm{M}$ acetic acid/sodium acetate/magnesium chloride hexahydrate adjusted to $\mathrm{pH} 4.5$ using $0.1 \mathrm{M} \mathrm{HCl} / \mathrm{NaOH}$ ). Cyclic voltammetry was carried out using a potential window of $0-1.0 \mathrm{~V}$ versus $\mathrm{Ag} / \mathrm{AgCl}$ and a scan rate of $0.1 \mathrm{~V} / \mathrm{s}$ with peak current $(\mu \mathrm{A})$ at each concentration recorded. The standards were also analysed using chronocoulometry and the resultant charge recorded. Chronocoulometry conditions employed a potential step of $0.2-0.8 \mathrm{~V}$, pulse width $10 \mathrm{~s}$, sample interval $0.01 \mathrm{~s}$, quiet time $0 \mathrm{~s}$ and sensitivity $1 \times 10^{6} \mathrm{~A} / \mathrm{V}$. The effect of scan rate $(0.05-0.1 \mathrm{~V} / \mathrm{s})$ on peak current was examined using a $0.5 \mathrm{mM}$ solution of 2-naphthol and peak current $(\mu \mathrm{A})$ versus square root of scan rate plotted. All background cyclic voltammetry and chronocoulometry measurements were made using $\mathrm{pH} 4.5$ acetate buffer in the absence of 2-naphthol under the same experimental conditions.

\subsubsection{Electrochemical Measurements with A549 Lung Epithelial Cells}

A549 human lung epithelial cells are an adherent cell line and were cultured in $T 75 \mathrm{~cm}^{2}$ polystyrene tissue culture flasks (Corning Inc) containing Roswell Park Memorial Institute (RPMI) medium with $25 \mathrm{mM}$ HEPES, $10 \%$ FBS, 1\% L-glutamine, $1 \%$ penicillin/streptomycin. The cells were cultured in a $5 \% \mathrm{CO}_{2}$ incubator at $37^{\circ} \mathrm{C}$. AP activity in cells was detected by seeding cells at a density of $4 \times 10^{4}$ cells per well into 8 microwells of a flat bottom transparent 96 well plate. RPMI medium $(100 \mu \mathrm{L})$ was aliquoted into another 8 microwells of the plate to act as a blank control. The plate was incubated for 24 hours in a $5 \% \quad \mathrm{CO}_{2}$ incubator at $37^{\circ} \mathrm{C}$, following which the medium was removed by blotting and each microwell was washed twice with sterile PBS. To each microwell, $5 \mathrm{mM}$ 2-NP dissolved in $\mathrm{pH} 4.5$ acetate buffer (presterilised using a $0.22 \mu \mathrm{m}$ hydrophilic filter) was added and the plate was incubated in $5 \% \mathrm{CO}_{2}$ at $37^{\circ} \mathrm{C}$ for 3 hours after which the supernatant was removed and aliquoted into fresh microwells. Cellular generation of 2-naphthol by AP was measured by cyclic voltammetry using a potential window of $0-1 \mathrm{~V}$ and a scan rate of $0.1 \mathrm{~V} / \mathrm{s}$.

The effect of cell number on 2-naphthol generation was investigated by seeding $0-40000$ cells per microwell on a 96 well plate and incubating the plate for 24 hours in a tissue culture incubator. After 24 hours the medium was removed and microwells were washed as described above. $10 \mathrm{mM}$ 2-NP was then added to the microwells for 1 hour. After this period the supernatant was removed and 2naphthol generation measured using the chronocoulometry conditions described above. Parameters such as the effect of substrate concentration $(0-10 \mathrm{mM})$ and substrate incubation time (0-120 minutes) were also scrutinised.

\subsubsection{Electrochemical Cytotoxicity Assay}

$\mathrm{CdCl}_{2}, \mathrm{NiCl}_{2}$ and pentachlorophenol (PCP) were selected as model toxins for this electronic cytotoxicity assay. Briefly, a 96 well plate was seeded with $4 \times 10^{4}$ cells per microwell and incubated for 24 hours under previously described conditions. Following incubation the medium was removed and each microwell washed three times with PBS. Fresh medium $(100 \mu \mathrm{L})$ was added to each microwell plus $100 \mu \mathrm{L}$ of $\mathrm{CdCl}_{2}(0-1000 \mu \mathrm{M}), \mathrm{NiCl}_{2}\left(0_{-}\right.$ $2000 \mu \mathrm{M})$ or PCP $(0-320 \mu \mathrm{M})$ prepared in either deionised water or PBS. All toxins were presterilised using a $0.22 \mu \mathrm{m}$ hydrophillic filter [9]. PCP standards were pre- 
pared from a stock solution of $150 \mathrm{mM}$ PCP dissolved in DMSO [25]. The control and all PCP standards were prepared such that no greater than $0.1 \% \mathrm{v} / \mathrm{v}$ DMSO was present in each sample. Cells were exposed to toxins for $24 \mathrm{~h}$ after which the toxins were removed and 2-naphthol generation measured by chronocoulometry following the previously described method. All cytotoxicity experiments (including controls) were carried out in triplicate.

\subsubsection{MTT Cell Viability Assay}

The cytotoxic effect of toxins was also assessed using the colorimetric MTT assay kit (Cayman chemical). Cells were seeded on a 96 well plate and exposed to toxins as described previously. After 24 hours of incubation, $10 \mu \mathrm{L}$ of $5 \mathrm{mg} / \mathrm{mL}$ MTT reagent was added to each sample. The plate was placed on an orbital shaker for 1 minute and then incubated for 4 hours in a tissue culture incubator. After this time the toxin and medium was removed from the microwells and $100 \mu \mathrm{L}$ of crystal dissolving solution was added to each well. The plate was then placed on an orbital shaker for 5 minutes and then back in the tissue culture incubator for 10 minutes to ensure dissolution of formazan crystals. Formazan generation was measured at $570 \mathrm{~nm}$ using a microplate reader.

\subsection{Design and Fabrication of a TOXOR Prototype for Cellular Enzyme Measurement}

\subsubsection{Design and Fabrication of Prototype TOXOR Device}

The TOXOR integrated mesofluidic/electronic detection device was designed using CorelDraw Graphics Suite X5 software and constructed using a thin film lamination approach (5 layers of polyester materials) bonded via chemical adhesion (Figure 1 and Scheme 2). Each layer was machined individually using an Epilog Zing $\mathrm{CO}_{2}$ laser cutter. The prototype was designed in such a way so as to allow a simplified version of the electrochemical AP cytotoxicity assay to be carried out using a single shot device.

The on-card subcomponents (Figures 1a-e) include combined fluidic and detection elements comprising:

(a) Sealed reagent cavity-pear-shaped (capacity $175 \mu \mathrm{L}$ ) in fluidic contact with the microwell and filled with enzyme substrate. This patented "membrane touch" activated component functions by the application of a manual (fingertip) force to a membrane above the cavity [26]. Fluid inside the cavity is then focussed towards a breakable valve and expelled into the microwell via a mesofluidic channel $(0.2 \times 7.96 \mathrm{~mm})$.

(b) Microwell-polystyrene coated polyester (capacity $40 \mu \mathrm{L}$, area $44.4 \mathrm{~mm}^{2}$ ) which allows for cell immobilisation and growth. During a cytotoxicity assay, the cells immobilised in the microwell were exposed to a toxin for a defined exposure time, following which it was then flooded with substrate (2-NP $10 \mathrm{mM})$ contained in the reagent cavity.

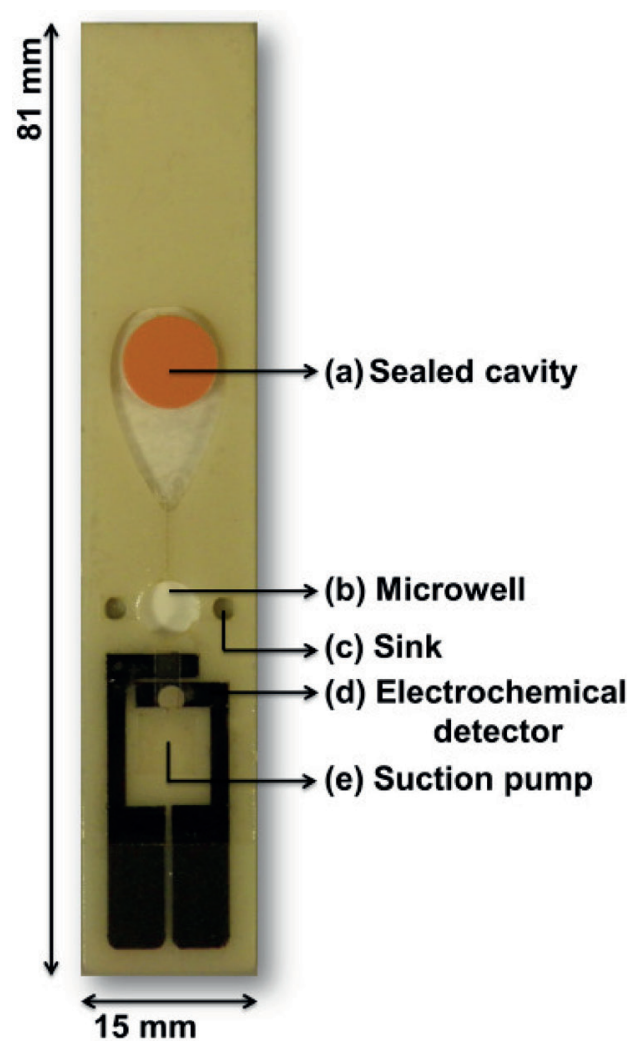

Fig. 1. Image shows a fully assembled TOXOR sensing device. Displayed is the reagent cavity, microwell with immobilised cells, sink-overflow device and printed sensor for enzyme activity measurement.

(c) Two "sinks" (volume $3.8 \mu \mathrm{L}$, area $11 \mathrm{~mm}^{2}$ ), enable drainage sites for cell media, toxin and excess substrate following flooding of the microwell and are connected via a channel $(3.5 \times 2.0 \mathrm{~mm})$.

(d) Electrochemical detector (volume $2.44 \mu \mathrm{L}$ ) consisting of stencil printed carbon working electrode $\left(3.8 \mathrm{~mm}^{2}\right)$ and $\mathrm{Ag} / \mathrm{AgCl}$ reference electrode $\left(2.8 \mathrm{~mm}^{2}\right)$ (Gwent $\mathrm{Ag} / \mathrm{AgCl}$ paste). The detector is also connected to the microwell through a channel $(0.2 \times 1.94 \mathrm{~mm})$ facilitating electrochemical analysis as the final stage in the assay.

(e) Suction pump consisting of a sealed air filled cavity (volume $25 \mu \mathrm{L}$ ) activated by application of external pressure to a membrane above the cavity expelling air into the microwell. When force is no longer applied to the membrane, liquid from the microwell is drawn into the electrochemical cell (d) for measurement.

\subsubsection{Measurement of Cellular Acid Phosphatase Activity Using Prototype TOXOR Biosensor}

This stage involved fabrication of a total of 8 TOXOR devices. Prior to assembly, all polyester layers were placed in a Telstar class II biosafety cabinet and sterilised under UV (254 nm) for 20 minutes [27]. The devices were then assembled by lamination inside the biosafety cabinet 
and then placed in a humidified atmosphere (petri dish containing filter paper soaked with sterile PBS). Prior to cell immobilisation, each microwell was coated with a layer $(<1 \mu \mathrm{m}$ thick $)$ of polystyrene $(30 \mathrm{mg} / \mathrm{mL}$ dissolved in THF). A $25 \mu \mathrm{L}$ aliquot of cell suspension (approximately 48000 cells) was added to the microwell of each device with incubation for $24 \mathrm{hrs}$ in a tissue culture incubator, following which the medium was removed. The microwells were subsequently washed twice with $20 \mu \mathrm{l}$ sterile PBS followed by the addition of $10 \mathrm{mM} 2-\mathrm{NP}$ or pH 4.5 acetate buffer ( $30 \mu \mathrm{L}$ in each case), returned to the petri dishes and placed back in the incubator for 2 hours. Subsequently 2-naphthol generation by cells was measured by cyclic voltammetry using the on-board electrochemical detector (d).

\section{Results}

\subsection{Naphthol Electrochemistry}

The electrochemistry of 2-naphthol was examined using both cyclic voltammetry and chronocoulometry. From the cyclic voltammogram of 2-naphthol (Figure 2A), an oxidation peak was evident at $E_{\mathrm{p}} \approx 0.70 \mathrm{~V}$ vs. $\mathrm{Ag} / \mathrm{AgCl}$ which was proportional to 2-naphthol concentration. No reduction peak was observed during the reverse scan over this range. The peak current was found to increase with scan rate from $0.05-0.1 \mathrm{~V} / \mathrm{s}$ while $E_{\mathrm{p}(\mathrm{ox})}$ shifted in a positive direction, confirming electrochemical irreversibility [28]. A graph of peak current versus the square root of scan rate (Figure 2B) resulted in a linear relationship $\left(R^{2}=0.97\right)$ confirming that electrochemical oxidation of 2-naphthol was under diffusion control. The charge arising from 2naphthol $(0-500 \mu \mathrm{M})$ dissolved in $\mathrm{pH} 4.5$ acetate buffer was measured using CC (Figure 2C and D) - data showed an increase in charge with 2-naphthol concentration $\left(R^{2}=\right.$ $0.990)$ and the limit of detection $(L O D)$ was found to be $22 \mu \mathrm{M}$.

\subsection{Electroanalysis of Epithelial Cell Phosphatase}

Following 24 hours incubation on a 96 well plate, 2-naphthol generation by viable A549 cells (indicative of cellular enzyme AP) was detected using cyclic voltammetry. The average current measured in the microwells containing 40000 cells was $984 \mathrm{nA}$ while the average current in microwells that had been incubated with culture medium only (negative control) was $269 \mathrm{nA}$. This background current is believed to be due to 2-NP chemical instability resulting in some hydrolysis to 2-naphthol (Figure 3A). The effect of cell number on 2-naphthol generation was investigated using chronocoulometry (Figure 3B). When the cell number was increased (0-40000 cells), 2-naphthol generation increased. The data suggested that $\geq 5000$ cells per microwell were required in order to generate a signal significantly different from the background charge.

The cytotoxicity assay proposed consisted of 2 steps firstly cells were exposed to a toxic chemical for $24 \mathrm{~h}$
(A)

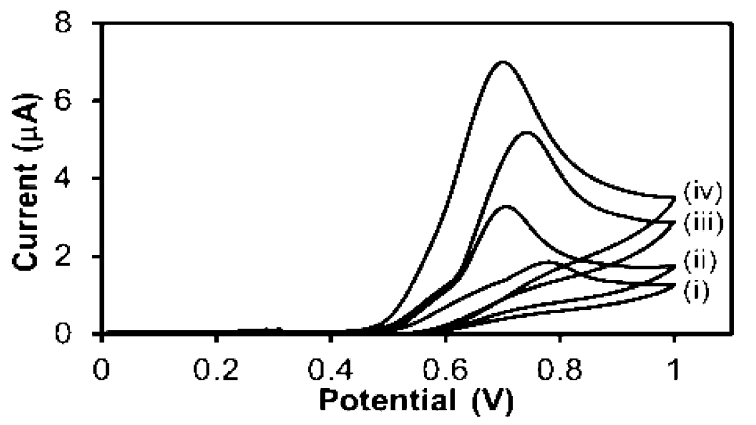

(B)

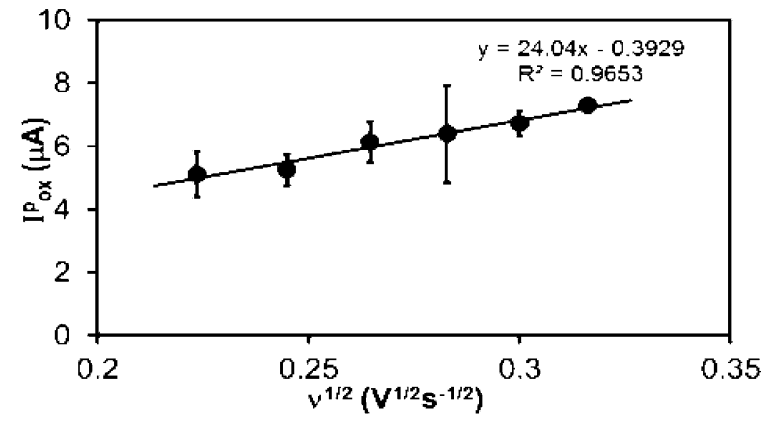

(C)

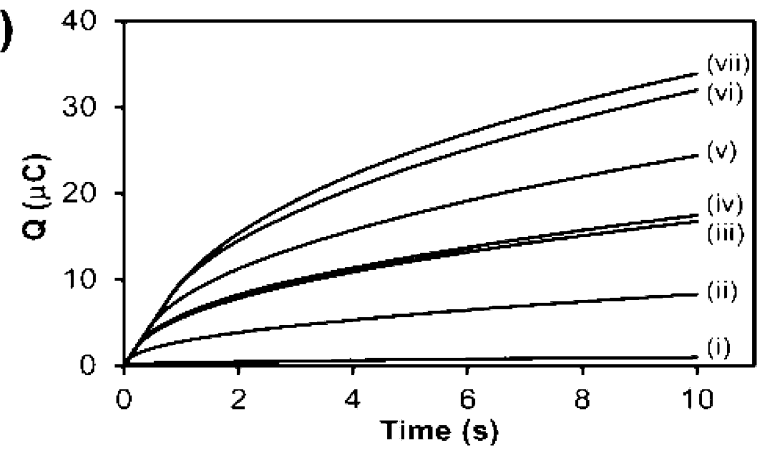

(D)

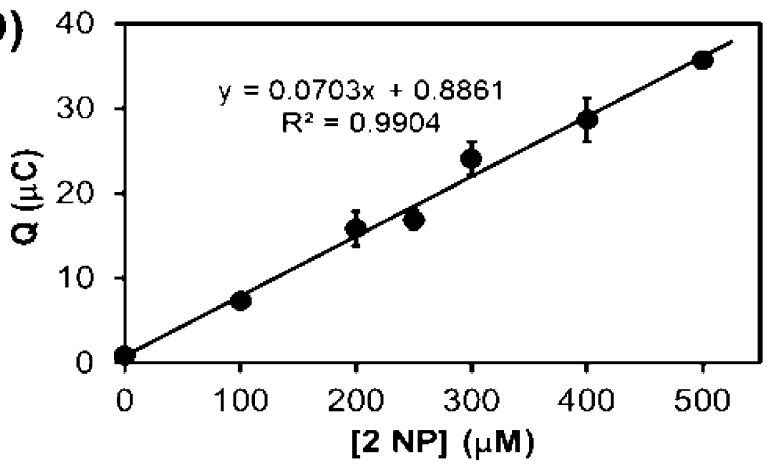

Fig. 2. (A) Cyclic voltammetry data for 2-naphthol: concentration $150-500 \mu \mathrm{M}$ (i-iv) $\mathrm{pH} 4.5$ acetate buffer, (B) graph of peak current versus square root of scan rate, (C) chronocoulometry data for 2-naphthol: concentration $0-500 \mu \mathrm{M}$ (i-vii) $\mathrm{pH} 4.5$ acetate buffer and (D) graph of $Q(\mu \mathrm{C})$ versus 2-naphthol concentration $(0-500 \mu \mathrm{M})$. Results are from a single experiment with measurements made in triplicate.

after which the toxin was removed. Secondly, $10 \mathrm{mM} 2-$ NP was added to the cells and after a defined period of time, the supernatant was removed and electrochemically analysed for 2-naphthol generation using a screen printed electrode. The effect of substrate incubation time on 2naphthol signal generation was investigated over the 
(A)

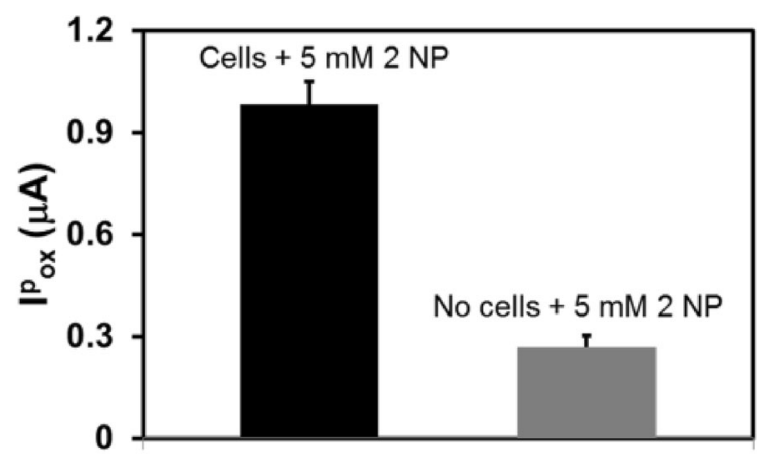

(B)

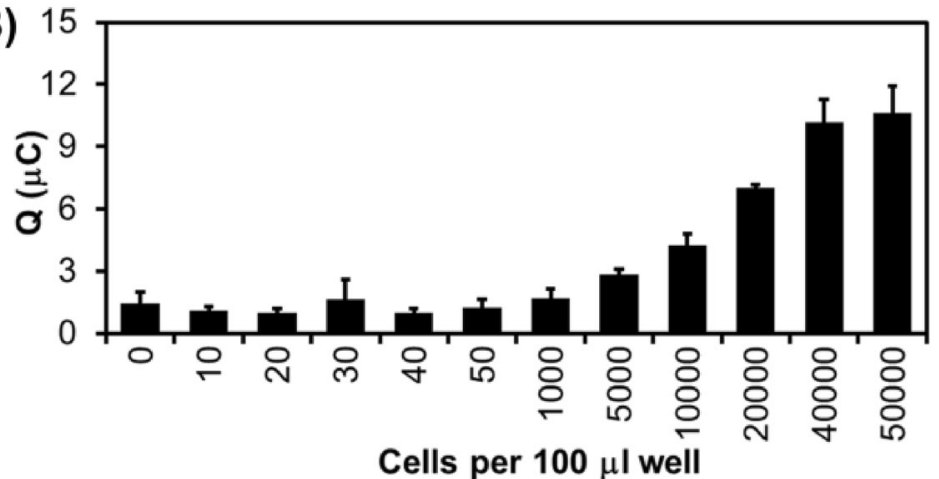

Fig. 3. (A) Electrochemical measurements of AP activity in A549 cells and (B) detector response to cell number. All data are from single experiments with measurements made in triplicate. Error bars indicated are standard deviation $(n=3)$.

range 1-120 minutes. Zero time measurements were made prior to substrate addition. The results of this experiment showed that over time the amount of 2-naphthol generated increased (Figure 4A) as expected and that the charge measured at 45 minutes $(11 \mu \mathrm{C})$ was $>3$ times that of the charge at zero minutes $(3 \mu \mathrm{C})$ confirming that 2-naphthol generation and reliable detection required at least 45 minutes following addition of 2-NP substrate.

In order to determine the substrate saturation concentration, 2-NP (0-10 mM) was prepared in $\mathrm{pH} 4.5$ acetate buffer and aliquoted into microwells of a 96 well plate containing 40000 cells per microwell. The plate was then placed in a tissue culture incubator for $1 \mathrm{hr}$ after which the supernatant was removed and aliquoted into microwells containing no cells with 2-naphthol generation due to AP activity measured by chronocoulometry. From the data shown in Figure 4B, the charge due to 2-naphthol generation increased and then plateaued $>5 \mathrm{mM}$, suggesting that the saturation level for the substrate was $5 \mathrm{mM}$ for 40000 cells.

\subsection{Cell Toxicity Studies Involving Cadmium and Nickel Metal Ions and Organochlorine Substance, PCP}

A reduction in AP activity was detected in cells following 24 hours exposure to each of $\mathrm{CdCl}_{2}, \mathrm{NiCl}_{2}$ and PCP. As the concentration of toxin increased 2-naphthol generation by cells decreased (Figure 5A, B and C). The results
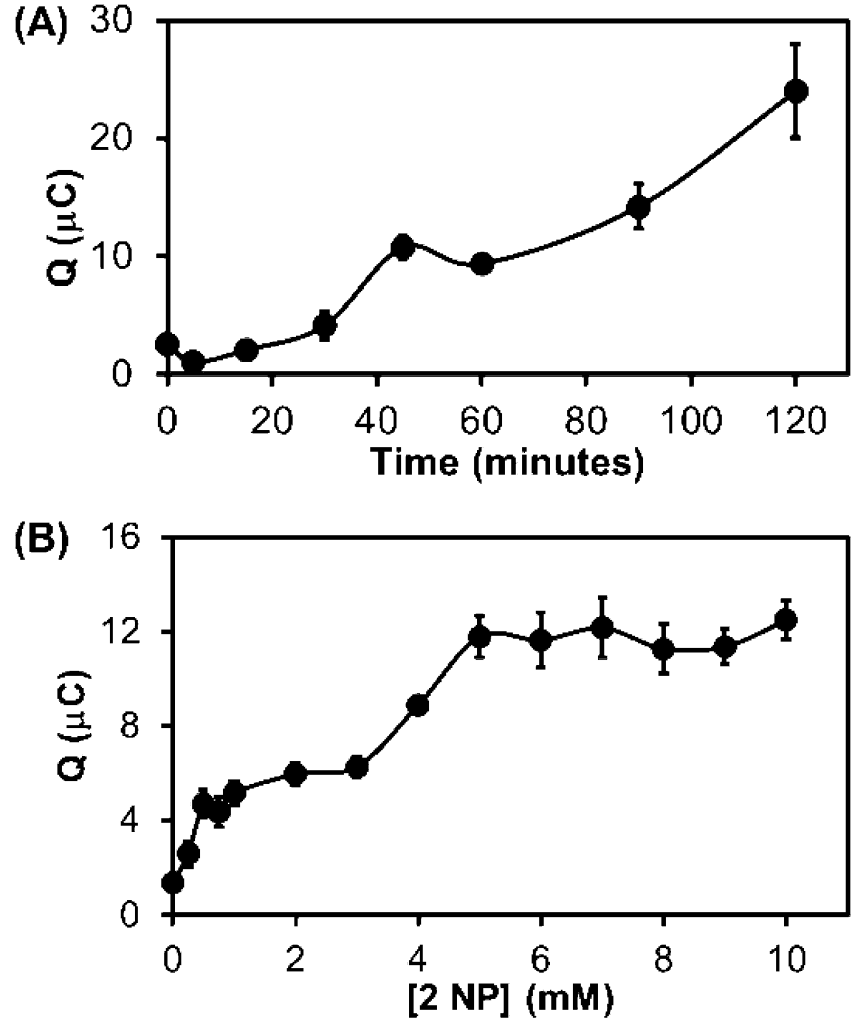

Fig. 4. Graphs showing the increase in 2-naphthol generation with (A) substrate addition time and (B) substrate concentration. All results are from single experiments with measurements made in triplicate. Error bars indicated are standard deviations $(n=3)$. 
Table 1 . Experimentally determined $I C_{50}$ values.

\begin{tabular}{lcc}
\hline Chemical & Electrochemical AP $I C_{50}(\mu \mathrm{M})$ & MTT $I C_{50}(\mu \mathrm{M})$ \\
\hline $\mathrm{CdCl}_{2}$ & 65 & 100 \\
$\mathrm{NiCl}_{2}$ & 330 & 350 \\
$\mathrm{PCP}$ & 60 & $>160$ \\
\hline
\end{tabular}

of all cytotoxicity experiments were analysed using a one way ANOVA plus Dunnetts comparison with $p<$ 0.05 considered statistically significant and the $I C_{50}$ values (the concentration of toxin resulting in $50 \%$ reduction in AP activity) determined (see Table 1 ).

The $I C_{50}$ values determined for $\mathrm{CdCl}_{2}$ and $\mathrm{NiCl}_{2}$ via the electrochemical AP cytotoxicity assay were comparable with those found using the standard MTT assay. They were also in good agreement with values reported in the literature. Fotakis et al. used the MTT assay to determine the cytotoxic effects of $\mathrm{CdCl}_{2}$ on rat and human hepatoma cell lines and reported $I C_{50}$ values of $100 \mu \mathrm{M}$ and $15 \mu \mathrm{M}$ respectively [29]. Ermolli et al. reported an $I C_{50}$ value of $600 \mu \mathrm{M}$ for $\mathrm{NiCl}_{2}$ in $\mathrm{HaCAT}$ human keratinocytes [30] while Rudzok et al. reported a value of $306 \mu \mathrm{M}$ for $\mathrm{Ni}^{2+}$ in human HepG2 cells [31]. Both researchers used the MTT assay to assess $\mathrm{Ni}^{2+}$ cytotoxicity.

The $I C_{50}$ value for PCP was found to be $60 \mu \mathrm{M}$ using the electrochemical AP cytotoxicity assay. The MTT assay data (Figure 5C Inset) indicated that no inhibition of mitochondrial dehydrogenase occured upon exposure of cells to concentrations of PCP up to $100 \mu \mathrm{M}$. An increase in mitochondrial dehydrogenase activity was detected when cells were exposed to PCP $\geq 120 \mu \mathrm{M}$ suggesting that the toxin was beginning to influence mitochondrial activity in the cells but not sufficiently enough to cause inhibition. The difference in sensitivity of the two assays towards PCP could be due to the mechanism of cytotoxicity of PCP in mammalian cells. PCP is known to be a powerful uncoupler of oxidative phosphorylation [32] which occurs in the mitochondria of mammalin cells, however some researchers have reported reduced sensitivity of the MTT assay towards PCP compared to other cytotoxicity assays [33]. Fernández Freire et al. investigated the cytotoxicity of PCP on vero monkey cells using the neutral red uptake assay and reported an $I C_{50}$ value of $5.5 \mu \mathrm{M}$ after 24 hours exposure [9]. It was suggested that PCP destabilises lysosomes before mitochondrial disfunction occurs and this was the reason for the reduced MTT assay sensitivity towards PCP. AP enzymes are located in the cytosol and lysosomes of cells [34] and it is possible that its activity was inhibited prior to that of mitochondrial dehydrogenase.

\subsection{Measurement of Cellular Acid Phosphatase Activity Using Prototype TOXOR Device}

The generation of 2-naphthol by approximately 48000 cells immobilised on the microwell component of eight in-house fabricated devices was scrutinised by cyclic vol-
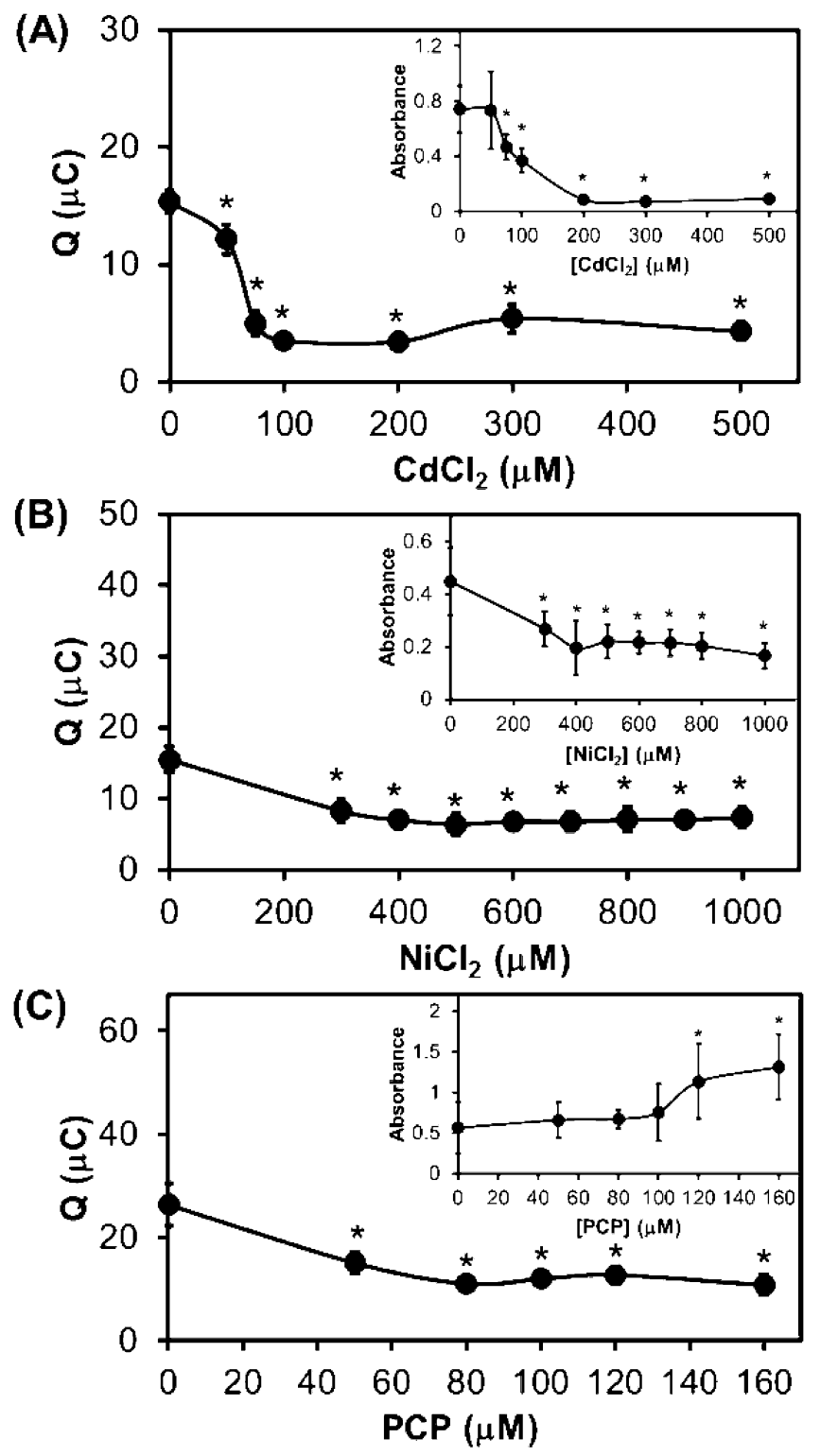

Fig. 5. Results of electrochemical AP cytotoxicity assays after $24 \mathrm{~h}$ exposure of cells to $\mathrm{CdCl}_{2}(\mathrm{~A}), \mathrm{NiCl}_{2}$ (B) and PCP (C) with MTT assay data shown as inserts. Results are the mean of 3 independent experiments. Error bars represent $S D, n=9$. Data points marked with an asterisk are statistically significant from controls $P<0.05$.

tammetry (Figure 6A). The average current measured by three TOXOR biosensors $(2.62 \mu \mathrm{A} \pm 0.91 \mu \mathrm{A})$ was almost three times greater than the background current $(0.93 \mu \mathrm{A})$ - acetate buffer exposed cells immobilised on three additional devices in the absence of substrate (Figure $6 \mathrm{~B}$ ). In the case of two of the devices, cells plus medium had migrated into the electrode channel during the $24 \mathrm{~h}$ incubation step, resulting in large capacitive currents which made cellular enzyme activity measurements impossible. This most likely occurred due to insufficient lamination/sealing during the fabrication stage, allowing air gaps to develop between the film layers. Integration 


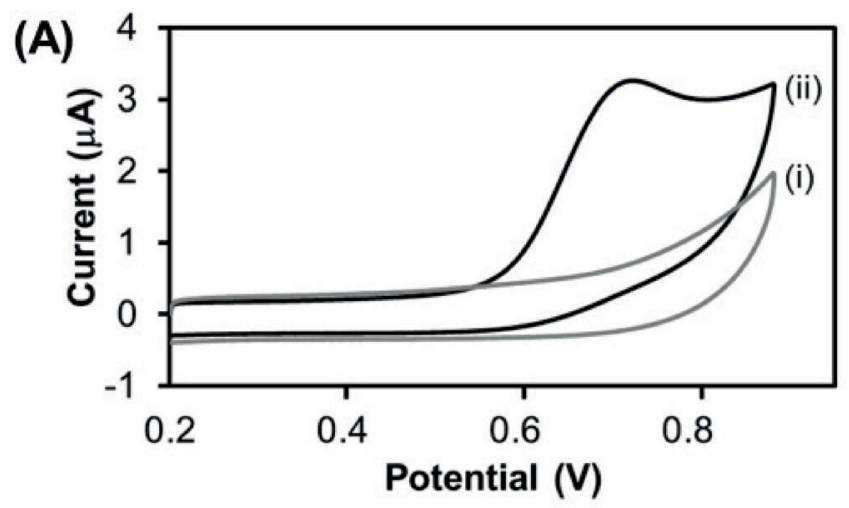

(B)

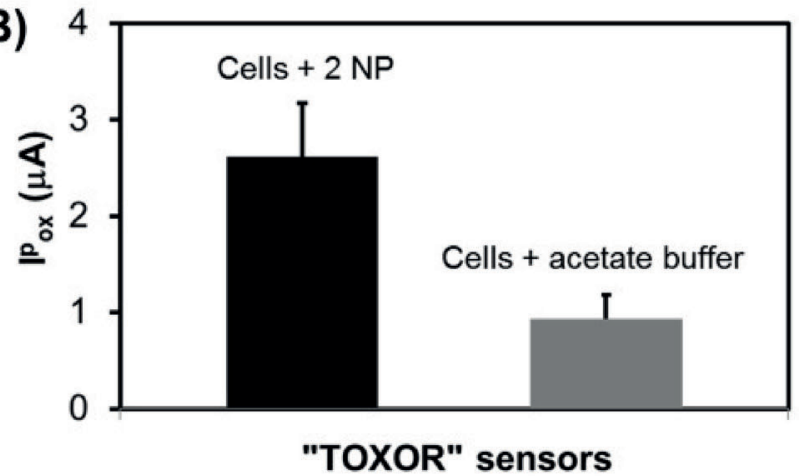

(C)

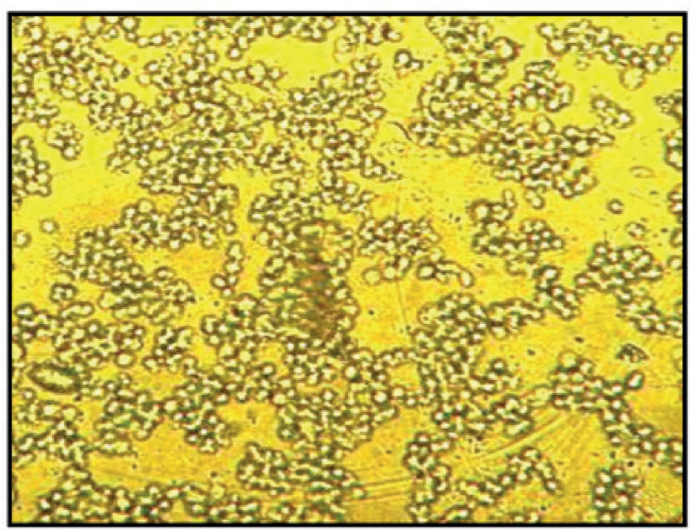

Fig. 6. (A) Cyclic voltammogram of 2-naphthol generation by A549 cells immobilised on TOXOR device; (i) cells $+2 \mathrm{NP}$ and (ii) cells + acetate buffer. (B) Average current measured after $2 \mathrm{~h}$ assay and (C) light microscopy image of A549 cells immobilised on TOXOR biosensor. Results are from a single experiment carried out in triplicate. Error bars are standard deviations $n=3$.

of a fluid retaining valve within this channel is being explored as a solution.

The immobilised cells were also viewed by replacing the base layer of the device with $100 \mu \mathrm{m}$ Melinex O PET, a transparent material which allowed imaging of cells under a Zeiss Axio A1 light microscope (Figure 6C).

\section{Conclusions}

In conclusion, cytotoxicity of selected environmental toxins was successfully demonstrated via detection of electrochemical changes in redox molecule generation in
A549 human lung epithelial cells. The effects of cell number, substrate addition time and substrate concentration were examined in order to determine optimum conditions for redox molecule measurement. The cytotoxic effects of $\mathrm{CdCl}_{2}, \mathrm{NiCl}_{2}$ and $\mathrm{PCP}$ resulted in a reduction in cellular AP activity after 24 hours exposure allowing $I C_{50}$ values to be determined. The $I C_{50}$ values obtained for $\mathrm{CdCl}_{2}$ and $\mathrm{NiCl}_{2}$ agreed with that found using the standard MTT cytotoxicity assay. However, in the case of PCP the $I C_{50}$ value was much lower suggesting that there was enhanced sensitivity with respect to the electrochemical assay relative to the MTT assay.

A portable cytotoxicity detector, comprising patented fluidic subcomponents was also designed and fabricated in house using inexpensive plastic materials. The capability of TOXOR for cellular AP activity measurement was successfully demonstrated and the next stage will extend this integrated bioelectronic device to full cytotoxicity assays. Future work will also address use of more robust fish cell lines with the aim of developing a device suitable for ecotoxicity screening applications.

\section{Acknowledgements}

The authors of this paper would like to acknowledge funding from the Irish Research Council (IRC) and Dr Santhosh Padmanabhan for graphical assistance.

\section{References}

[1] K. R. Rogers, Anal. Chim. Acta 2006, 568, 222-231.

[2] European Chemicals Agency, Understanding REACH (Online), available at http://echa.europa.eu/web/guest/regulations/reach/understanding-reach (accessed 22 June 2014).

[3] D. Arndt, M. Moua, J. Chen, R. Klaper, Environ. Sci. Technol. 2013, 47, 9444-9452.

[4] S. Jose, P. Jayesh, A. Mohandas, R. Philip, I. S. Bright Singh, Mar. Environ. Res. 2011, 71, 169-177.

[5] F. Tan, M. Wang, W. Wang, Y. Lu, Toxicol. In Vitro 2008, $22,164-170$

[6] T. Mosmann, J. Immunol. Meth. 1983, 16, 55-63.

[7] C. Korzeniewski, D. M Callewaert, J. Immunol. Meth. 1983, 25, 313-320.

[8] M. C. Little, D. J. Gawkrodger, S. MacNeil, Brit. J. Dermatol. 1996, 134, 199-207.

[9] P. Fernández Freire, V. Labrador, J. M. Pérez Martín, M. J. Hazen, Toxicology 2005, 210, 37-44.

[10] N. F. Pasco, R. J. Weld, J. M. Hay, R. Gooneratne, Anal. Bioanal. Chem. 2011, 400, 931-945.

[11] M. S. Thakur, K. V. Ragavan, J. Food. Sci. Technol. 2012, 50, 625-641.

[12] M. Farré, L. Kantiani, S. Pérez, D. Barceló, $\operatorname{Tr} A C$ 2009, 28 , $170-185$.

[13] J. J. Pancrazio, J. P. Whelan, D. A. Borkholder, W. Ma, D. A. Stenger, Ann. Biomed. Eng. 1999, 27, 697-711.

[14] T. J. O'Shaughnessy, J. J. Pancrazio, Anal. Chem. 2007, 79, $8838-8845$.

[15] Q. Liu, C. Wu, H. Cai, N. Hu, J. Zhou, P. Wang, Chem. Rev. 2014, DOI: $10.1021 / \mathrm{cr} 2003129$, in press.

[16] I. Giaever, C. R. Keese, Proc. Acad. Sci. 1984, 81, 37613764. 
[17] D. Zhang, Y. Zhang, L. Zheng, Y. Zhan, L. He, Biosens. Bioelectron. 2013, 42, 112-113.

[18] J. M. Seiffert, M-O. Baradez, V. Nischwitz, T. Lekishvili, H. Goenaga-Infante, D. Marshall, Chem. Res. Toxicol. 2012, 25 , $140-152$.

[19] L. Brennan, M. W. Widder, L. E.J. Lee, W. H. van der Schalie, Toxicol. in Vitro 2012, 26, 736-745.

[20] D. J. Adlam, D. E. Woolley, Sensors 2010, 10, 3732-3740.

[21] Y. Wang, Q. Chen, X. Zeng, Biosens. Bioelectron. 2010, 25, $1356-1362$.

[22] O. J. Yoon, C. H. Kim, I-Y. Sohn, N-E. Lee, Sens. Actuators B, Chem. 2013, 188, 454-461.

[23] X. Zhu, H. Qin, J. Liu, Z. Zhang, Y. Lu, X. Yuan, D. Wu, J. Hazard. Matter. 2014, 271, 210-219.

[24] C. Yu, Z. Zhu, L. Wang, Q. Wang, N. Bao, H. Gu, Biosens. Bioelectron. 2014, 53, 142-147.

[25] G. Shan, M. Ye, B. Zhu, L. Zhu, Chemosphere 2013, 93, 2101-2107.

[26] Micro-reagent handler and cartridge assembly P10977EP00 No. 12192551.5:Filed 04/11/13
[27] A. H. Dewilde, G. Wang, K. A. Marx, J. M. Therrien, S. J. Braunhut, Anal. Biochem. 2013, 439, 50-61.

[28] D. T. Sawyer, A. Sobokowiak, J. L. Roberts Jr, in Electrochemistry for Chemists, 2ednd edWiley, New York, 1995.

[29] G. Fotakis, J. A. Timbrell, Toxicol. Lett. 2006, 160, 171-177.

[30] M. Ermolli, C. Menné, G. Pozzi, M-Á. Serra, L. A. Clerici, Toxicology 2001, 159, 22-31.

[31] S. Rudzok, U. Schlink, O. Herbath, M. Bauer, Toxicol. App. Pharm. 2010, 244, 336-343.

[32] E. C. Weinbach, J. Biol. Chem. 1954, 210, 545-550.

[33] G. Repetto, A. Jos, M. J. Hazen, M. L. Molero, A. del Peso, M. Salguero, P. del Castillo, M. C. Rodríguez-Vicente, M. Repetto, Toxicol In Vitro 2001, 15, 503-509.

[34] A. Siddiqua, A. Saeed, R. Naz, M. Sherazi, S. Abbas, A. Saeed, Int. J. Agr. Biol. 2012, 14, 223-228.

Received: August 11, 2014 Accepted: August 27, 2014 Published online: October 16, 2014 